\title{
Micro-RNAs miR125b and miR137 are frequently upregulated in response to capecitabine chemoradiotherapy of rectal cancer
}

\author{
M. SVOBODA ${ }^{1,3,4}$, L. IZAKOVICOVA HOLLA ${ }^{2}$, R. SEFR ${ }^{4}$, I. VRTKOVA ${ }^{3}$, \\ I. KOCAKOVA ${ }^{4}$, B. TICHY ${ }^{5}$ and J. DVORAK ${ }^{3}$ \\ ${ }^{1}$ Oncobios Research Group, P.O. B. 51, CZ 61200 Brno; ${ }^{2}$ Department of Pathophysiology, Medical Faculty, Masaryk \\ University, Kamenice 3, CZ 62500 Brno; ${ }^{3}$ Department of Animal Morphology, Physiology and Genetics, \\ Mendel University, Zemedelska 1, CZ 61300 Brno; ${ }^{4}$ Masaryk Memorial Cancer Institute, Zluty kopec 7, Brno; \\ ${ }^{5}$ Center of Molecular Biology and Gene Therapy, University Hospital Brno, Cernopolni 9, CZ 62500 Brno, Czech Republic
}

Received April 2, 2008; Accepted May 30, 2008

DOI: 10.3892/ijo_00000038

\begin{abstract}
There is increasing evidence that some microRNAs change their levels in reaction to xenobiotic challenge. The aim of this study was to test the possible involvement of micro-RNAs in response to standard anticancer treatment. Tumor biopsies from 35 patients with rectal cancer before therapy and parallel tumor biopsies from 31 patients two weeks after starting preoperative capecitabine chemoradiotherapy were taken. The expression levels of single miRNA species were measured using TaqMan Micro-RNA assays after reverse transcription from isolated total RNAs. Many micro-RNAs (miR10a, miR21, miR145, miR212, miR339, miR361) responded to chemoradiotherapy in individual tumor samples, but there was profound intertumoral variability. However, other two micro-RNAs miR125b, miR137 showed a significant increase in median expression levels after starting therapy in most samples. Moreover, our results for the first time show that higher induced levels of miR125b and miR137 are associated with worse response to the therapy.
\end{abstract}

\section{Introduction}

Micro-RNAs are short RNA molecules that function as posttranscriptional regulators of gene expression in all eukaryotic organisms investigated so far $(1,2)$. There are hundreds of different micro-RNAs known in man (3).

General mechanism of micro-RNA action in animal and human cells is the inhibition of translation after forming a complex similar to the RNA-interference-induced silencing complex (RISC) (4). The other mechanism of influencing gene expression is the induction of mRNA target cleavage

Correspondence to: Dr Miroslav Svoboda, Oncobios Research Group, P.O. B. 51, CZ 61200 Brno, Czech Republic

E-mail: svoboda@oncobios.org

Key words: micro-RNA, miR125b, miR137, miR21, preoperative chemoradiotherapy, rectal cancer
(5-7). The levels of some miRNAs are frequently changed in cancer (8-10). Certain miRNAs function as oncogenes and others could function as tumor suppressors (11).

Over $52 \%$ of miRNA genes are located in cancer-associated fragile chromosomal sites (12). The constitutive silencing of miR15, miR16 in CLL (13) and constitutive BIC (miR155) expression in childhood lymphomas (14), is associated with these fragile chromosomal sites.

There are several examples of rapidly induced change of miRNA expression as a consequence of various external stimuli like hypoxia (15), TPA treatment (16) and gemcitabine (17). This indicates that miRNAs might be involved in dynamic regulatory circuits and that micro-RNA levels do not change only as a consequence of chromosome translocation (deletion). Many miRNAs have promoting or inhibiting functions in apoptosis and cell growth (18). There are many p53 downstream targets among miRNA species, which reflect differential miRNA expression in colorectal cell line harboring a functional p53 gene versus cell line carrying a non-functional gene (19).

It is well known that preoperative chemoradiotherapy with capecitabine (a 5-fluorouracil prodrug) induces significant tumor shrinkage in $>80 \%$ colorectal cancer patients $(20,21)$. This shrinkage is substantial in $20-40 \%$ patients. Conversely, there is a significant percentage of patients $(20 \%)$ that do not respond, or only minimally, to the therapy and their tumors continue to grow $(20,22)$. We speculated that if micro-RNAs play the expected role in oncogenesis, then therapy-responding tumors would exhibit change of oncogenic and tumor suppressor micro-RNAs toward normal expression levels typical for adjacent non-tumor tissue after starting efficient therapy. On the other hand, micro-RNAs in tumors nonresponding to the therapy would not exhibit such a change. To test this hypothesis, we examined several micro-RNAs possessing known or predicted functions in apoptosis, p53mediated regulatory events, the determination of lifespan (miR125b), connected with TNM status (miR31), or connected with epithelial-to-mesenchymal transition (miR21, miR137).

Most of recent miRNA experimental work published in other reports was done on cell lines. There have been several reports dealing with the micro-RNA level response to experi- 
mental treatment of cell lines and xenografts using common anticancer drugs gemcitabine (17), 5-fluorouracil (23) as well as cancer inducer tamoxifen (24). The micro-RNA expression levels were measured in NCI-60 panel and careful data analysis uncovered a possible role of several micro-RNAs in chemosensitivity and chemoresistance in vitro $(25,26)$. Manipulation by expression levels of several miRNAs led up to 4-fold differences in growth inhibition caused by certain anticancer drugs on NCI-60 panel cell lines (26). Recently, American retrospective study on formalin-fixed paraffinembedded (FFPE) samples revealed that expression levels of hsa-let-7g and hsa-miR-181b were strongly associated with clinical response to S-1, another 5-fluorouracil-based antimetabolite (27). These findings forced us to examine changes of selected micro-RNAs (selection on the basis of literature search) in tumors from patients differently responding to standard preoperative therapy of rectal cancer. Rectal cancer, unlike many other forms, offers almost unique opportunity to study changes caused by introduced treatment at acceptable risk and patient's discomfort during rectoscopy, which is a routine part of the medical examination. Microexcision biopsies were taken from the same rectal cancers before therapy, and subsequently two weeks after starting preoperative chemoradiotherapy treatment. The TNM stage and tumor regression grade were compared to particular miRNA levels. The schedule design for taking parallel samples two weeks after starting therapy was based on our previous observation that several important markers like mRNAs for thymidylate synthase or thymidine phosphorylase and others are substantially upregulated at this time (28; unpublished data).

\section{Patients and methods}

Patients aged 33-76, median 59 years, 24 male and 11 female, ECOG performance status of 0-2 (29), who had histologically confirmed rectal adenocarcinoma without distant metastases, stages II-III (cT3-cT4, cN0, cM0 or T2-T4, $\mathrm{cN}+, \mathrm{cM} 0$ ) according to IUCC (30) were included in the study. The Ethics Committee of the Masaryk Memorial Cancer Institute approved the treatment protocol. All patients gave written informed consent.

Preoperative capecitabine was administered orally, at a dose of $825 \mathrm{mg} / \mathrm{m}^{2}$ twice a day, $2 \mathrm{~h}$ prior to radiotherapy for $\sim 5.5$ weeks from the first to the last day of radiotherapy. Threedimensional conformal pelvic radiotherapy was delivered using linear accelerator with $18 \mathrm{MV}$ photon beams and with an isocentric technique (source-axis distance of $100 \mathrm{~cm}$ ). Radiation therapy was given in conventional fractionation in locally curative dosage. The daily fraction dose was $1.8 \mathrm{~Gy}$, applied five days per week up to cumulative dose of $45 \mathrm{~Gy}$, boosting up to $50.4 \mathrm{~Gy}$, during the period of 5.5 weeks.

The standard total rectal resection or amputation (31), leaving tumor-free resection margins including total mesorectal excision (TME) was performed within the 6th week after completion of radiotherapy. Clinical cTNM stage (preceding a therapy) was based on the endorectal ultrasonography, CT and colonoscopy.

Pathological examination after surgery involved the former tumor-bearing area and its macroscopic and microscopic description. The extent of tumor response to therapy was investigated microscopically. Dworak et al were the first to introduce tumor regression grading based on microscopic examination (32). Our department of pathology, however, has routinely been using similar Mandard's tumor regression (TRG 1-5) criteria (33) adapted to colon cancer (34) and designed later. Therefore, we used this TRG grading system in this study.

Tumor microexcisions $\left(1-3 \mathrm{~mm}^{3}\right)$ were taken before starting therapy and again after two-week therapy. Tumor samples were immersed immediately in RNA Later solution (Quiagen GmbH, Germany).

The RNAs from bioptic samples were isolated by the standard TRIzol method (35). RNAs were quantified using Eppendorf spectrophotometer (Eppendorf, Germany). Quality of RNA was tested by standard denaturing electrophoresis and also analyzed on Agillent 2100 Bioanalyzer.

The micro-RNA levels in pre-treatment and treatment samples were determined by means of stem-loop RT-Real Time PCR (36). The Real-Time PCR using stem-loop reverse transcription and TaqMan detection is a relatively novel method for quantification of small RNAs (snoRNAs, miRNAs) with high specificity and sensitivity (36) and high degree of reproducibility (37) at minimum load (typically $10 \mathrm{ng}$ of total RNA).

cDNA reverse transcription was performed using genespecific primers, TaqMan Micro-RNA Reverse Transcription Kit and 10 ng RNA according to TaqMan Micro-RNA Assay Protocol. Stem-loop RT primer (50 nM), 1X RT buffer, $10 \mathrm{mM}$ dNTP each, RNase inhibitor $0.19 \mu 1$, MultiScribe reverse transcriptase $1 \mu \mathrm{l}$, water and RNA were mixed in $15 \mu \mathrm{l}$ final reaction volume and incubated for $30 \mathrm{~min}$ at $16^{\circ} \mathrm{C}, 30 \mathrm{~min}$ at $42^{\circ} \mathrm{C}, 5 \mathrm{~min}$ at $85^{\circ} \mathrm{C}$, cooled and kept at $4^{\circ} \mathrm{C}$.

Real-Time PCR mix contained $10 \mu 1$ TaqMan Universal Master Mix No Amp Erase UNG, $1 \mu 1$ 20x Assay Mix from TaqMan Micro-RNA Assay Kit (both from Applied Biosystems, Foster City, USA), RT product $1.33 \mu \mathrm{l}$ and water in final volume of $20 \mu 1$.

Real-Time PCR was performed on Applied Biosystems 7000 instrument in a 96-well optical plate under following conditions: $95^{\circ} \mathrm{C} 10-\mathrm{min}$ initial denaturation, 40 cycles of $95^{\circ} \mathrm{C}$ for $15 \mathrm{sec}$ and $60^{\circ} \mathrm{C}$ for $40 \mathrm{sec}$. RNU6B RNA was used as an active reference endogenous control. The threshold cycle CT was determined using default instrument settings. Adjacent non-tumorous mucosa before treatment was used as a calibrator. Detailed protocols and other information concerning micro-RNAs will be found on website http: \lwww.oncobios. org following publication.

Data analysis. We used comparative $\mathrm{C}_{\mathrm{T}}$ method approach $\left(2^{-\Delta \Delta C t}\right)$ for the calculation of relative miRNA expression (Applied Biosystems User Bulletin \#2, P/N 4303859). Expression of miRNA was related to RNU6B RNA as an endogenous active reference and related to adjacent nontumor colon mucosa as a calibrator. These miRNA relative expression levels before starting therapy were designated as a control group versus a sample group representing data two weeks after starting therapy.

In an initial pilot experiment, miRNA relative expression levels from 10 tumors before therapy and paired samples 
Table I. Variability of potential reference RNA expression.

\begin{tabular}{lccc}
\hline Reference RNA & Average CT & s & CV \\
\hline RNU6B & 27.58 & 0.61 & 2.21 \\
miR33 & 34.52 & 0.83 & 2.41 \\
miR198 & 34.43 & 1.27 & 3.68 \\
RNU19 & 24.48 & 1.57 & 6.43 \\
RNU43 & 24.36 & 1.66 & 6.83 \\
Let 7a & 22.41 & 1.96 & 8.74 \\
\hline
\end{tabular}

from the same tumors two weeks after starting therapy were subjected to logarithmic transformation and analyzed by means of microarray data analysis tool TIGER Multiple Experiment Viewer (TMEV) software package (38). Nonsupervised hierarchical clustering of logarithmically transformed expression levels was performed using average linkage and Euclidean distance after global median normalization. Standard statistical analyses were calculated using MedCalc and Statistica version 7 software. Statistical significance was set at $\mathrm{p} \leq 0.05$.

\section{Results}

Since no extensive study concerning evaluation of suitable references for micro-RNA experiments in CRC exists, it was necessary to find suitable endogenous controls with low variability and with low treatment-induced change. We evaluated small nuclear RNAs U6B, U19, U43 and microRNAs Let-7a, miR33 and miR198. Based on threshold cycle $\mathrm{C}_{\mathrm{T}}$ values coefficients of variability $(\mathrm{CV})$ were calculated for each potential reference in 20 tumors including both samples before and/or after two-week therapy. The lowest variability including lowest treatment-induced change was observed in U6B RNA levels (Table I). Therefore, U6B RNA was used as an endogenous control for the determination of relative microRNA expression. U6 RNA is frequently used as a reference in micro-RNA array experiments $(9,16)$.

We performed a pilot experiment to find the micro-RNAs that would give the most consistent changes induced by the therapy. Tumor samples from 6 randomly selected patients before starting therapy and their paired tumor samples after two weeks of treatment were evaluated in this initial experiment. Real-Time PCRs using TaqMan Micro-RNA Assay Kits were performed and relative expressions of miR10a, miR21, miR31, miR125b, miR137, miR145, miR212, miR339 and miR361 were determined. Relative expression levels were calculated by means of $2^{-\Delta \Delta \mathrm{Ct}}$ method and logarithms of resulting relative gene expression levels were subjected to a non-supervised hierarchical clustering by means of TMEV software as cited in Patients and methods. Fig. 1 shows that several samples exhibited certain change in each particular micro-RNA after therapy. However, there was a profound intertumoral variability and some micro-RNA

\begin{tabular}{lll}
\hline-3.0 & 0.0 & 3.0
\end{tabular}

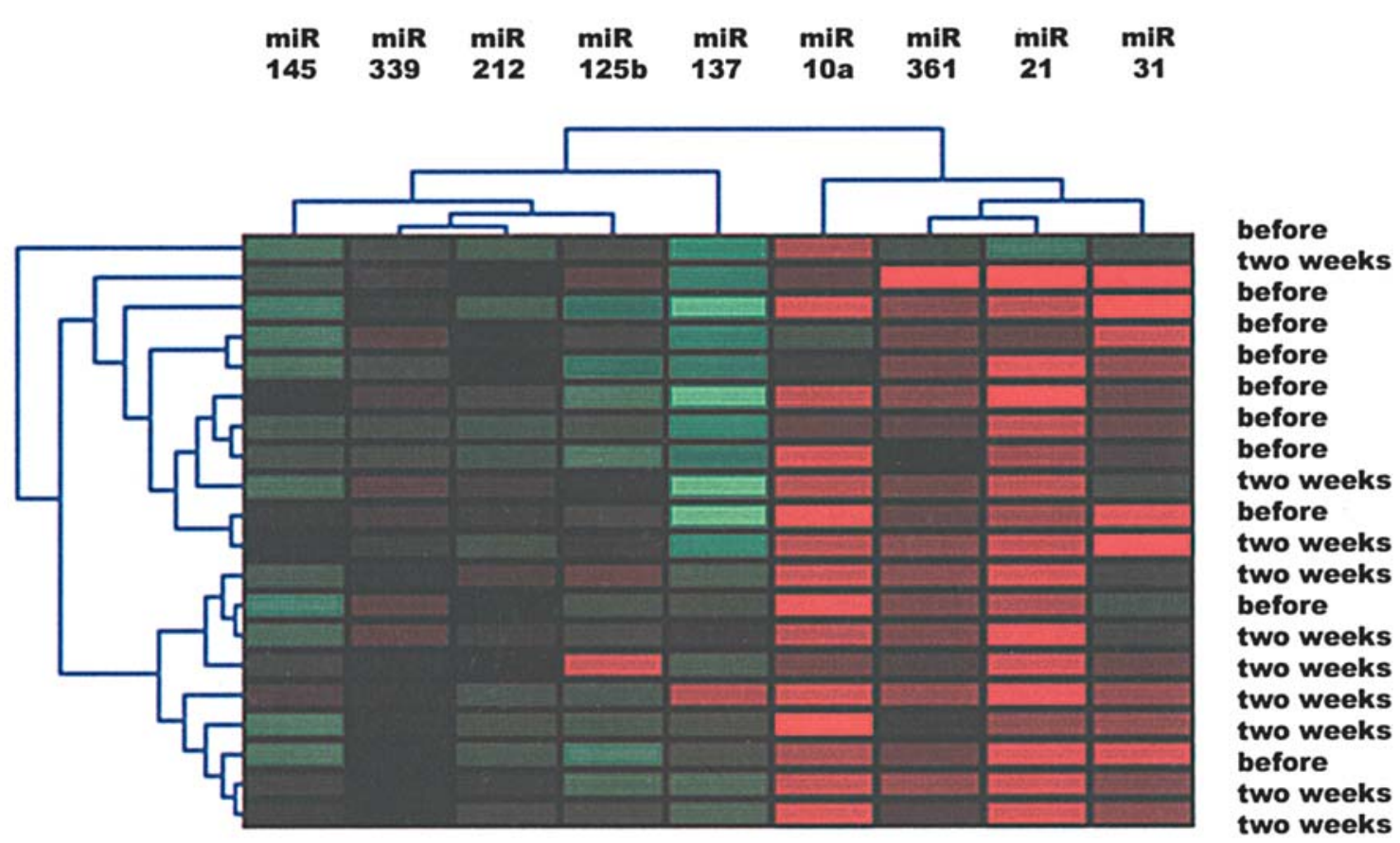

Figure 1. Hierarchical clustering of micro-RNA expression. Before, samples before starting therapy; two weeks, paired tumor samples after two-week therapy. 


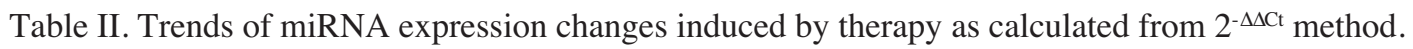

A, Fraction of tumors where miRNAs are upregulated and relation of miR125b and miR137 expression (paired samples from 31 tumors).

\begin{tabular}{lccc}
\hline \multirow{2}{*}{ miRNA } & \multicolumn{2}{c}{ Fraction of upregulated samples $(\mathrm{N}=31)$} & $\frac{\text { Down-regulated (N=31) }}{\%}$ \\
\cline { 2 - 3 } miR125b & No. of tumors & $\%$ & 32 \\
miR137 & 21 & 68 & 16 \\
\hline
\end{tabular}

r, before therapy

Correlation coefficient miR125b vs.137* (31 paired samples)

\begin{tabular}{llll}
\hline 0.422 & 0.018 & 0.086 & 0.645
\end{tabular}

B, Fold upregulation and statistical significance from all tumors (unpaired samples, two-tailed Mann-Whitney U test).

\begin{tabular}{lcccccc}
\hline miRNA & $\begin{array}{c}\text { Median level } \\
\text { before* }(\mathrm{N}=35)\end{array}$ & $\begin{array}{c}\text { 95\% confidence } \\
\text { interval }\end{array}$ & $\begin{array}{c}\text { Level after 2 weeks } \\
\text { therapy }(\mathrm{N}=31)\end{array}$ & $\begin{array}{c}95 \% \text { confidence } \\
\text { interval }\end{array}$ & $\begin{array}{c}\text { Fold change } \\
\text { (median ratio) }\end{array}$ & $\begin{array}{c}\text { Mann-Whitney } \\
\text { U test p-value }\end{array}$ \\
\hline miR125b & 0.463 & $0.182-1.260$ & 1.173 & $0.362-4.420$ & $2.5 \times$ & 0.05 \\
miR137 & 0.037 & $0.016-0.110$ & 0.243 & $0.092-0.341$ & $6.5 \times$ & 0.0004 \\
\hline
\end{tabular}

Table III. Relationship between significant tumor regression and the therapy induced miRNA median level fold changes and p-values of miRNA levels depending on regression grade.

\begin{tabular}{lccccc}
\hline Regression grade & No. of samples & miR125b fold change & p-value & miR137 fold change & p-value \\
\hline TRG 1-2 & $\mathrm{N}=18$ & 2.3 & 0.090 & 2.9 & 0.058 \\
TRG 3-5 & $\mathrm{N}=13$ & 2.0 & $\mathbf{0 . 0 2 3}$ & 6.3 & $\mathbf{0 . 0 0 2}$ \\
\hline
\end{tabular}

Bold, statistically significant $\mathrm{p} \leq 0.05$, Wilcoxon two-tailed paired test.

species did not exhibit response in several samples and/or exhibited adverse trends in different tumors (increase in one and decrease in the other tumor after therapy compared to the status before therapy). Micro-RNAs miR125b, miR137 only showed significant induction and exhibited the same expression trends in most samples two weeks after starting therapy (Fig. 1). Micro-RNAs miR125b, miR137 were therefore chosen for further analysis in total sample set.

Statistical analysis of expression levels determined by standard comparative $\mathrm{C}_{\mathrm{T}}$ method shows non-parametric distribution of data (Shapiro-Wilk and Lilliefors tests). We therefore used non-parametric testing for all data (Wilcoxon paired test and Mann-Whitney-U test).

Statistical analysis shows a weak correlation between levels of the two examined micro-RNAs before starting therapy (Table IIA). Our results show that median levels of both miR137 and miR125b were upregulated two weeks after starting therapy in most samples although statistical significance of miR $125 \mathrm{~b}$ upregulation $\mathrm{p}=0.05$ is at the edge of the significance level. Micro-RNAs exhibited extensive inter-

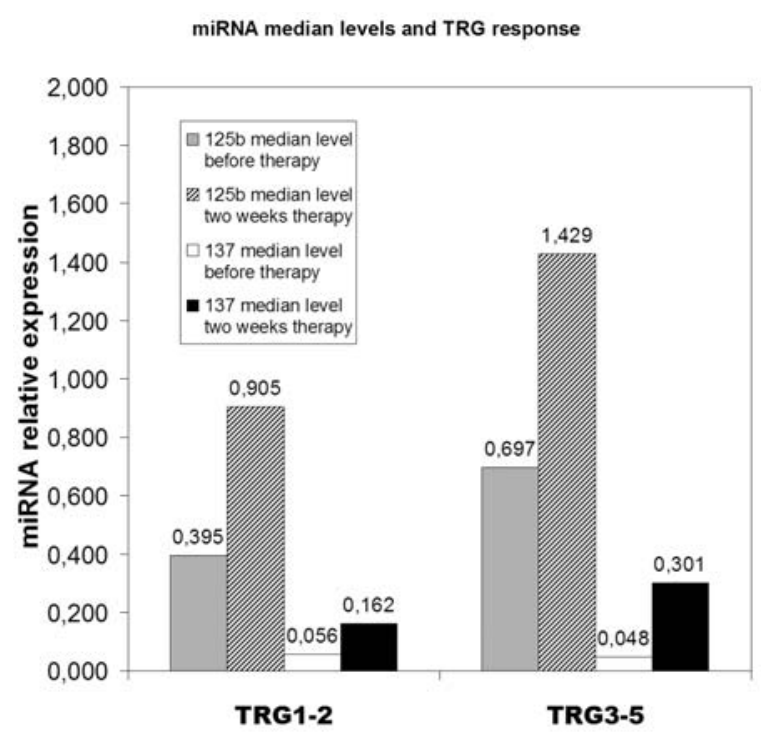

Figure 2. Relationship between significant tumor regression after therapy and the therapy induced miRNA median level changes. 
Table IV. Relationship between tumor stage based on TNM classification and the therapy induced miRNA median level fold changes and p-values (Wilcoxon paired test) depending on tumor stage.

\begin{tabular}{lccccc}
\hline Tumor grade & No. of samples & miR125b fold change & p-value & miR137 fold change & p-value \\
\hline ypT0-1 & $\mathrm{N}=9$ & 2.3 & 0.36 & 3.72 & 0.20 \\
ypT2 & $\mathrm{N}=11$ & 1.9 & 0.32 & 5.51 & 0.10 \\
ypT3/4 & $\mathrm{N}=11$ & 3.9 & $\mathbf{0 . 0 0 9 8}$ & 5.54 & $\mathbf{0 . 0 0 1}$ \\
\hline
\end{tabular}

Table V. Fold changes and p-values of miRNA levels depending on node state.

\begin{tabular}{lccccc}
\hline Tumor grade & No. of samples & miR125b fold change & p-value & miR137 fold change & p-value \\
\hline cN0 & 8 & $\mathbf{1 0 . 0}$ & 0.148 & $\mathbf{1 2 . 1}$ & $\mathbf{0 . 0 0 8}$ \\
cN1 & 14 & 2.0 & 0.153 & 2.2 & 0.078 \\
cN2 & 9 & 1.5 & 0.055 & $\mathbf{3 . 0}$ & $\mathbf{0 . 0 3 9}$ \\
ypN0 & 20 & 2.2 & 0.058 & $\mathbf{4 . 9}$ & $\mathbf{0 . 0 2 6}$ \\
ypN1/2 & 11 & $\mathbf{6 . 9}$ & $\mathbf{0 . 0 3 2}$ & $\mathbf{4 . 8}$ & $\mathbf{0 . 0 0 2}$ \\
\hline
\end{tabular}

${ }^{a}$ Wilcoxon test.

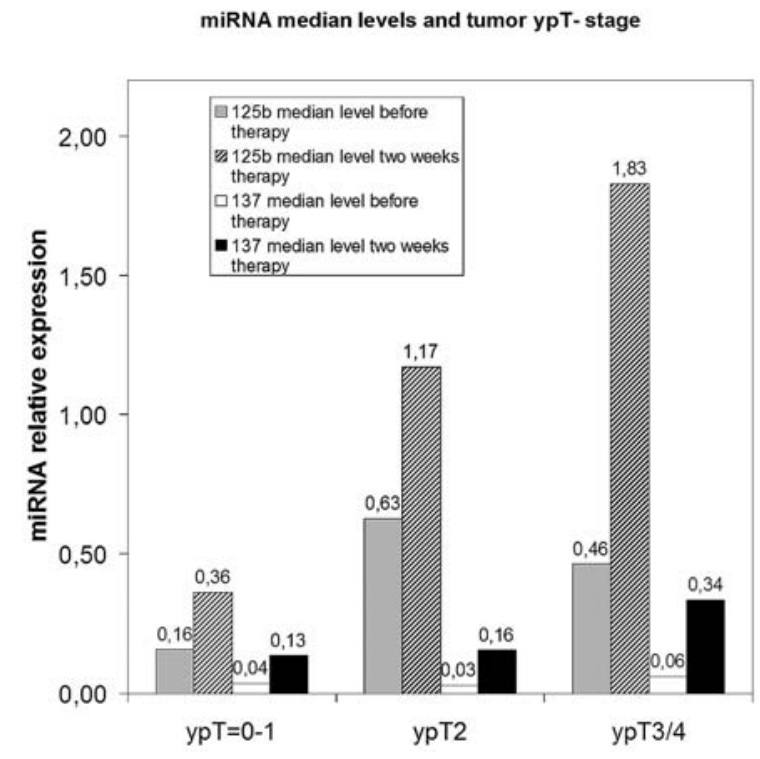

Figure 3. Relationship between tumor stage after therapy based on TNM classification and the therapy induced miRNA median level change.

tumoral level variability both before treatment and in samples taken two weeks after starting therapy (see 95\% confidence intervals in Table IIB).

The observation of frequent upregulation after starting therapy could support our initial hypothesis that miRNA levels tend to change to normal levels after efficient tumor destruction as both miR125b and miR137 are known to be down-regulated in CRC lines and colorectal and breast carcinomas (9). Therefore, we investigated whether the changes of miRNA levels are associated with immediate tumor responses. We investigated the relationship between significant tumor regression (TRG 1-2) and increase in

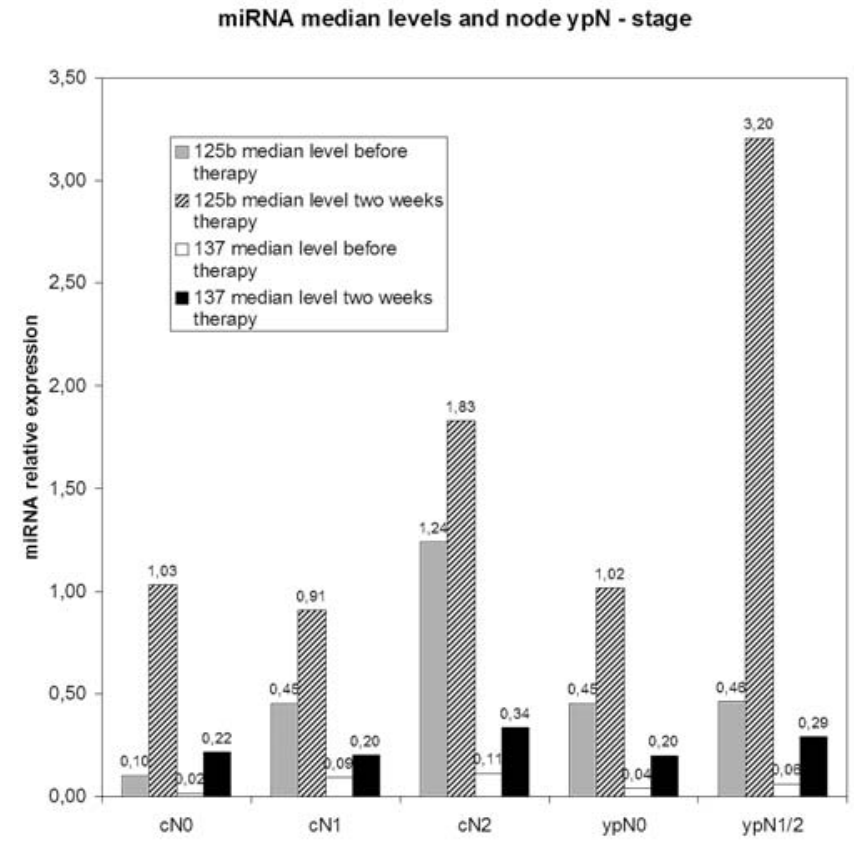

Figure 4. Relationship between node status based on TNM classification and the therapy induced miRNA median level changes.

miRNA levels after starting therapy as well as role of downstaging. Only tumors exhibiting weak response or no response (TRG 3-5) show statistically significant upregulation (Table III and Fig. 2). Substantially responding tumors (TRG 1-2) also show increase in median levels after starting therapy, however the differences are not statistically significant, although very close to significant level in the case of miR137 $(\mathrm{p}=0.058)$. Similarly, both micro-RNAs exhibit a certain level of differences depending on tumor ypT-state and node cN-state of TNM classification (Tables IV and V, Figs. 3 and 4). 
However, all ypT stages according to TNM classification show miRNA median level increase two weeks after starting therapy, both miR125b and miR137 have statistically significant upregulation in ypT3 tumors only (Table V and Fig. 3). There are profound differences of miR125b levels between ypT0/1, ypT2 and ypT3 stages or between different TRG stages already before starting therapy (Figs. 2 and 3). Only the patients with locally advanced rectal cancers without metastases were studied; therefore, M-state of TNM classification is not included in tables and figures.

\section{Discussion}

The micro-RNA miR125b is known to be down-regulated in breast cancer (9) and CRC lines (39). The miR125b shows high similarity and may represent a mammalian ortholog of Caenorhabditis elegans micro-RNA lin-4 (40). Lin-4 is known to be involved in worm lifespan regulation (41). It was found that lin-4 affects life span through the insulin/insulin-like growth factor pathway (41). Similarly, human miR125b was shown to target IGFR-1, as well as VEGF and VEGFR (39). IGF-1 homeostasis in mouse also influences longevity $(42,43)$ and high levels of IGF-1 are associated with promoting growth of normal and malignant tissues $(44,45)$. Therefore, the upregulation of miR125b observed in our experiments two weeks after starting therapy could down-regulate IGFR-1, VEGF and VEGFR and consecutively suppress the tumor growth and angiogenesis. The suggested hypothetic mechanism of possible role of miR125b through insulin/insulin-like growth factor pathway is supported by knowledge that down-regulation of IGF-1 reduces proliferation and enhances apoptotic events in prostate (46).

Micro-RNA miR125b is more expressed in differentiated cells and miR $125 \mathrm{~b}$ is also necessary for maintaining their proliferation (47). Further targets of miR125b are ERBB2 and ERBB3 oncogenes in vitro. The retroviral constructs overexpressing either miR-125a or miR-125b resulted in suppression of ERBB2 and ERBB3 at both the transcript and protein level in SKBR3 cells (48). Cells overexpressing miR125a-or miR125b were impaired in their anchoragedependent growth and exhibited reduced migration and invasion capacities (48). On the other hand, the proliferationpromoting role of miR $125 \mathrm{~b}$ in differentiated cells could mean that situation is more complicated. Although $125 \mathrm{~b}$ is upregulated in all TNM categories, the highest and the only statistically significant change is observed in the groups of ypT3/4 and ypN1/2 patients (no downstaging and positive node involvement). It is well known that T3/4 stage or node involvement is usually associated with worse prognosis than T0-T2, N0. Therefore, higher induction of miR125 is associated with a worse prognosis. There are profound differences of miR125b levels between ypT0/1, ypT2 and ypT3/4 patient groups already before starting therapy (Figs. 2 and 3). Patients with low stage tumors have lower miRNA induction than patients with more advanced cancers. These results indicate that we should use carefully the term oncogene or tumor suppressor in connection with certain miRNAs. Micro-RNA miR125b is down-regulated in several cancers and may be considered a tumor suppressor from this point of view. However, in this study we show no downstaging and less regression (poor response) in the tumors with the highest upregulation of miR $125 \mathrm{~b}$ level two weeks after starting therapy. Non-responding tumors exhibited induction of miR125b level close to and above normal levels of adjacent non-tumor mucosa while miR125b expression did not reach mucosal levels in responding tumors. It shows that simple restoration of normal miR $125 \mathrm{~b}$ level could not regain the normal phenotype in colon cancer cells. On the other hand, it shows that miR $125 \mathrm{~b}$ probably functions in tumors similarly to its ortholog Lin-4 in worms (41) because miR125b like Lin-4 also improves survival in overexpressing cells.

Micro-RNA miR137 was found to be mildly upreguleted during epithelial-to-mesenchymal transition after TGF-ß challenge and is upregulated during mitosis (49), however substantially down-regulated in glioblastoma compared to normal neurons (50) and down-regulated in colorectal cancers as well (39).

Our results show that miR137 is significantly upregulated only in the most advanced T-stage (Table IV). However there is no association of miR137 induction with stage of node involvement (Table V and Fig. 4).

Contrary to the above-mentioned miR $125 \mathrm{~b}$ although upregulated, miR137 in tumors did not reach the original median value of normal tissue (Fig. 3). We therefore speculate that low miR137 levels could be important to maintain tumor state.

Micro-RNA miR145 is known to be down-regulated in colorectal cancer (51). We used miRNA levels from adjacent non-tumor colon mucosa as a calibrator in our pilot experiment (Fig. 1). We showed that most tumors have miR145 levels down-regulated compared to mucosal level which is in accordance with the literature (51-53). Similarly miR21 is known to be upregulated in many tumors $(54,55)$ and miR31 is known to be upregulated in CRC (39). Our observations are in accordance with these results (Fig. 1) and support validity of our experimental data.

\section{Acknowledgements}

We thank the private sponsors, Czech Science Foundation (Grant GACR 310/06/0827) and Ministry of Healthcare of the Czech Republic (VVZ5714, VVZ5718, VVZ5752) for providing financial support.

\section{References}

1. Wheeler G, Valoczi A, Havelda Z, et al: In situ detection of animal and plant MicroRNAs. DNA Cell Biol 26: 251-255, 2007.

2. Gesellchen V and Boutros M: Managing the genome: microRNAs in Drosophila. Differentiation 72: 74-80, 2004.

3. Leung AK and Sharp PA: Function and localization of microRNAs in mammalian cells. Cold Spring Harb Symp Quant Biol 71: 29-38, 2006.

4. Gregory RI and Shiekhattar R: MicroRNA biogenesis and cancer. Cancer Res 65: 3509-3512, 2005.

5. Yekta S, Shih IH and Bartel DP: MicroRNA-directed cleavage of HOXB8 mRNA. Science 304: 594-596, 2004.

6. Lee YS, Nakahara K, Pham JW, et al: Distinct roles for Drosophila Dicer-1 and Dicer-2 in the siRNA/miRNA silencing pathways. Cell 117: 69-81, 2004.

7. Yu Z, Raabe T and Hecht NB: MicroRNA Mirn122a reduces expression of the post-transcriptionally regulated germ cell transition protein 2 (Tnp2) messenger RNA (mRNA) by mRNA cleavage. Biol Reprod 73: 427-433, 2005. 
8. Calin GA and Croce CM: MicroRNA signatures in human cancers. Nat Rev Cancer 6: 857-866, 2006.

9. Iorio MV, Ferracin M, Liu CG, et al: MicroRNA gene expression deregulation in human breast cancer. Cancer Res 65: 7065-7070, 2005 .

10. McManus MT: MicroRNAs and cancer. Semin Cancer Biol 13: 253-258, 2003.

11. Hammond SM: MicroRNAs as tumor suppressors. Nat Genet 39: 582-583, 2007.

12. Calin GA, Sevignani C, Dumitru CD, et al: Human microRNA genes are frequently located at fragile sites and genomic regions involved in cancers. Proc Natl Acad Sci USA 101: 2999-3004, 2004.

13. Calin GA, Dumitru CD, Shimizu M, et al: Frequent deletions and down-regulation of micro-RNA genes miR15 and miR16 at $13 q 14$ in chronic lymphocytic leukemia. Proc Natl Acad Sci USA 99: 15524-15529, 2002.

14. Metzler M, Wilda M, Busch K, et al: High expression of precursor microRNA-155/BIC RNA in children with Burkitt lymphoma. Genes Chromosomes Cancer 39: 167-169, 2004.

15. Hua Z, Lv Q, Ye W, et al: MiRNA-directed regulation of VEGF and other angiogenic factors under hypoxia. PLoS ONE 1: e116, 2006.

16. Kasashima K, Nakamura Y and Kozu T: Altered expression profiles of microRNAs during TPA-induced differentiation of HL-60 cells. Biochem Biophys Res Commun 322: 403-410, 2004.

17. Peters I, Tossidou I, Achenbach J, et al: IGF-binding protein-3 modulates TGF-beta/BMP-signaling in glomerular podocytes. J Am Soc Nephrol 17: 1644-1656, 2006.

18. Cheng AM, Byrom MW, Shelton J, et al: Antisense inhibition of human miRNAs and indications for an involvement of miRNA in cell growth and apoptosis. Nucleic Acids Res 33: 1290-1297, 2005

19. Xi Y, Shalgi R, Fodstad O, et al: Differentially regulated microRNAs and actively translated messenger RNA transcripts by tumor suppressor p53 in colon cancer. Clin Cancer Res 12: 2014-2024, 2006

20. Slampa P, Kocakova I, Sefr R, et al: Neoadjuvant treatment for locally advanced rectal adenocarcinoma with concomitant radiotherapy and oral capecitabine. J BUON 9: 33-40, 2004.

21. Kim JC, Kim TW, Kim JH, et al: Preoperative concurrent radiotherapy with capecitabine before total mesorectal excision in locally advanced rectal cancer. Int J Radiat Oncol Biol Phys 63: 346-353, 2005.

22. Das P, Lin EH, Bhatia S, et al: Preoperative chemoradiotherapy with capecitabine versus protracted infusion 5-fluorouracil for rectal cancer: a matched-pair analysis. Int J Radiat Oncol Biol Phys 66: 1378-1383, 2006.

23. Rossi L, Bonmassar E and Faraoni I: Modification of miR gene expression pattern in human colon cancer cells following exposure to 5-fluorouracil in vitro. Pharmacol Res 56: 248-253, 2007.

24. Pogribny IP, Tryndyak VP, Boyko A, et al: Induction of microRNAome deregulation in rat liver by long-term tamoxifen exposure. Mutat Res 619: 30-37, 2007.

25. Blower PE, Verducci JS, Lin S, et al: MicroRNA expression profiles for the NCI-60 cancer cell panel. Mol Cancer Ther 6: 1483-1491, 2007.

26. Blower PE, Chung JH, Verducci JS, et al: MicroRNAs modulate the chemosensitivity of tumor cells. Mol Cancer Ther 7: 1-9, 2008.

27. Nakajima G, Hayashi K, Xi Y, et al: Non-coding MicroRNAs hsa-let-7g and hsa-miR-181b are associated with chemoresponse to S-1 in colon cancer. Cancer Genomics Proteomics 3: 317-324, 2006

28. Kocakova I, Svoboda M, Kubosova K, et al: Preoperative radiotherapy and concomitant capecitabine treatment induce thymidylate synthase and thymidine phosphorylase mRNAs in rectal carcinoma. Neoplasma 54: 447-453, 2007.

29. Oken MM, Creech RH, Tormey DC, et al: Toxicity and response criteria of the Eastern Cooperative Oncology Group. Am J Clin Oncol 5: 649-655, 1982

30. Sobin LH and Wittekind C: TNM Classification of Malignant Tumours. 6th edition. John Wiley \& Sons, New Jersey, 2002.

31. Faerden AE, Naimy N, Wiik P, et al: Total mesorectal excision for rectal cancer: difference in outcome for low and high rectal cancer. Dis Colon Rectum 48: 2224-2231, 2005.
32. Dworak O, Keilholz L and Hoffmann A: Pathological features of rectal cancer after preoperative radiochemotherapy. Int $\mathbf{J}$ Colorectal Dis 12: 19-23, 1997

33. Mandard AM, Dalibard F, Mandard JC, et al: Pathologic assessment of tumor regression after preoperative chemoradiotherapy of esophageal carcinoma. Clinicopathologic correlations. Cancer 73: 2680-2686, 1994.

34. Bouzourene H, Bosman FT, Seelentag W, et al: Importance of tumor regression assessment in predicting the outcome in patients with locally advanced rectal carcinoma who are treated with preoperative radiotherapy. Cancer 94: 1121-1130, 2002.

35. Chomczynski P: A reagent for the single-step simultaneous isolation of RNA, DNA and proteins from cell and tissue samples. Biotechniques 15: 532-537, 1993.

36. Chen C, Ridzon DA, Broomer AJ, et al: Real-time quantification of microRNAs by stem-loop RT-PCR. Nucleic Acids Res 33: e179, 2005.

37. Liang Y, Ridzon D, Wong L, et al: Characterization of microRNA expression profiles in normal human tissues. BMC Genomics 8: 166,2007

38. Saeed AI, Sharov V, White J, et al: TM4: a free, open-source system for microarray data management and analysis. Biotechniques 34: 374-378, 2003.

39. Bandres E, Cubedo E, Agirre X, et al: Identification by realtime PCR of 13 mature microRNAs differentially expressed in colorectal cancer and non-tumoral tissues. Mol Cancer 5: 29-39, 2006.

40. Lagos-Quintana M, Rauhut R, Yalcin A, et al: Identification of tissue-specific microRNAs from mouse. Curr Biol 12: 735-739, 2002.

41. Boehm M and Slack F: A developmental timing microRNA and its target regulate life span in C. elegans. Science 310: 1954-1957, 2005.

42. Richardson A, Liu F, Adamo ML, et al: The role of insulin and insulin-like growth factor-I in mammalian ageing. Best Pract Res Clin Endocrinol Metab 18: 393-406, 2004.

43. Gami MS and Wolkow CA: Studies of Caenorhabditis elegans DAF-2/insulin signaling reveal targets for pharmacological manipulation of lifespan. Aging Cell 5: 31-37, 2006.

44. Burgaud JL, Resnicoff M and Baserga R: Mutant IGF-I receptors as dominant negatives for growth and transformation. Biochem Biophys Res Commun 214: 475-481, 1995.

45. Wu X, Fan Z, Masui H, et al: Apoptosis induced by an antiepidermal growth factor receptor monoclonal antibody in a human colorectal carcinoma cell line and its delay by insulin. J Clin Invest 95: 1897-1905, 1995.

46. Ohlson N, Bergh A, Persson ML, et al: Castration rapidly decreases local insulin-like growth factor-1 levels and inhibits its effects in the ventral prostate in mice. Prostate 66: 1687-1697, 2006.

47. Lee YS, Kim HK, Chung S, et al: Depletion of human microRNA miR-125b reveals that it is critical for the proliferation of differentiated cells but not for the down-regulation of putative targets during differentiation. J Biol Chem 280: 16635-16641, 2005 .

48. Scott GK, Goga A, Bhaumik D, et al: Coordinate suppression of ERBB2 and ERBB3 by enforced expression of micro-RNA miR-125a or miR-125b. J Biol Chem 282: 1479-1486, 2007.

49. Zavadil J, Narasimhan M, Blumenberg M, et al: Transforming growth factor-beta and microRNA:mRNA regulatory networks in epithelial plasticity. Cells Tissues Organs 185: 157-161, 2007.

50. Ciafre SA, Galardi S, Mangiola A, et al: Extensive modulation of a set of microRNAs in primary glioblastoma. Biochem Biophys Res Commun 334: 1351-1358, 2005

51. Michael MZ, SM OC, van Holst Pellekaan NG, et al: Reduced accumulation of specific microRNAs in colorectal neoplasia. Mol Cancer Res 1: 882-891, 2003.

52. Akao Y, Nakagawa Y and Naoe T: MicroRNA-143 and -145 in colon cancer. DNA Cell Biol 26: 311-320, 2007.

53. Cummins JM, He Y, Leary RJ, et al: The colorectal microRNAome. Proc Natl Acad Sci USA 103: 3687-3692, 2006

54. Chan JA, Krichevsky AM and Kosik KS: MicroRNA-21 is an antiapoptotic factor in human glioblastoma cells. Cancer Res 65: 6029-6033, 2005.

55. Volinia S, Calin GA, Liu CG, et al: A microRNA expression signature of human solid tumors defines cancer gene targets. Proc Natl Acad Sci USA 103: 2257-2261, 2006. 